\title{
SOLIDIFICATION CHARACTERISTICS OF ADVANCED NICKEL-BASE SINGLE CRYSTAL SUPERALLOYS
}

\author{
R.A. Hobbs ${ }^{1}$, S. $\operatorname{Tin}^{1}$, C.M.F. Rae ${ }^{1}$, R.W. Broomfield ${ }^{2}$ and C.J. Humphreys ${ }^{1}$ \\ ${ }^{1}$ University of Cambridge / Rolls-Royce University Technology Partnership, Department of Materials Science and Metallurgy; \\ Pembroke Street; Cambridge, CB2 3QZ, UK \\ ${ }^{2}$ Rolls-Royce plc; PO Box 31; Derby, DB24 8BJ
}

Keywords: single crystal solidification, solid-liquid partitioning, freckle formation.

\begin{abstract}
Twenty-two Ni-base superalloy compositions were investigated to assess the influence of the constituent elements on their solidification characteristics. Increasing the amount of $\mathrm{Cr}$ and $\mathrm{Mo}$ in high refractory single crystal alloys appears to reduce the extent of microsegregation of the dense refractory elements, W and Re. This is likely to be advantageous for maintaining single crystal solidification since alloys containing elevated levels of $\mathrm{W}$ and $\mathrm{Re}$ are prone to the formation of macroscopic grain defects during single crystal solidification. These findings suggest that elemental interactions between $\mathrm{Cr}, \mathrm{Mo}, \mathrm{W}$ and Re need to be considered when optimising alloys for high temperature creep properties. $\mathrm{Ru}$ additions also appear beneficial not only through stabilisation of the microstructure with respect to topological-close-packed (TCP) phase formation but also by reducing the degree to which $\mathrm{Re}$ partitions to the dendrite core. Linear regression has been applied to predict the solid-liquid partition coefficients for the major constituent elements and therefore provide an indication of the susceptibility of a given composition to freckle formation during directional solidification.
\end{abstract}

\section{Introduction}

To improve the performance and efficiency of gas turbine engines, single crystal Ni-base superalloy turbine blades have been increasingly alloyed with dense refractory elements to enhance high temperature creep properties. As single crystal compositions have become more heavily alloyed, the ease of manufacturing and processing has decreased, primarily due to formation of solidification related grain defects. Moreover, the recent trend of adding ruthenium to single crystal Ni-base superalloys has led to substantial increases in raw material costs, thus making manufacturing yield improvements through the reduction of casting defects of paramount importance. Hence, assessment of the solidification characteristics of these complex multi-component alloys and understanding the various elemental interactions is critical during the development of advanced single crystal Ni-base superalloys with improved high temperature properties and long term stability.

With respect to high temperature structural properties, dramatic improvements in nickel-base superalloys have been achieved through a combination of both alloy and processing developments. With increasing alloy strength at elevated temperatures, it has been necessary to develop new processing techniques to exploit advances in alloy design. Advances in processing have enabled equiaxed polycrystalline components to be replaced by directionally solidified columnar or monocrystalline structures. Since polycrystalline grain structures are susceptible to creep failure and cracking along grain boundaries under centrifugal forces at elevated temperatures, minimization of the grain boundaries enhances the high temperature structural properties [1]. The process of directional solidification not only produces a turbine blade capable of a longer and more reliable service life but also allows the removal of grain boundary strengthening elements that tend to depress the solidus temperature of the alloy $[2,3]$.

Single crystal superalloys have been through three generations of development. Important in the enhancement of high temperature creep resistance from generation to generation has been the addition of dense refractory elements such as Ta, W, Mo and, above all, Re. An increasing concentration of Re, from 0 to 3 to 6 wt.\%, is the principal factor distinguishing the three generations. The high melting temperatures and large atomic diameters associated with these refractory elements make these additions potent solid solution strengtheners. Refractory additions have however not been without their disadvantages.

The breakdown of single crystal solidification is often attributed to the presence of elevated levels of dense refractory elements that partition strongly to either the solid or liquid phase during solidification and ultimately result in the formation of freckle chains. Additions of Re and W partition strongly to the dendritic regions during solidification, thus depleting the liquid solute of these dense elements as solidification progresses. This gives rise to large density imbalances between the bulk liquid and the less dense solute contained within the dendritic mushy zone. The compositional differences lead to the formation of convective instabilities that create solute-rich plumes which solidify as channels of equiaxed grains, or freckles. Research into solidliquid elemental partitioning during solidification has demonstrated the importance of $\mathrm{Ta}, \mathrm{W}$ and Re segregation in promoting the formation of these grain defects [4-9].

\section{Experimental Procedure}

The as-cast structures of twenty-two Ni-base superalloy compositions were investigated to assess the influence of the constituent elements on their solidification characteristics. The compositions in wt.\% of the alloys investigated are listed in Table 1. A Cameca SX-100 electron microprobe with five wavelength dispersive spectrometers (WDS) was used to quantify the degree to which the constituent elements of each alloy segregates during solidification. This provided representative compositional information from the dendrite cores to the interdendritic regions. The solid-liquid partition coefficients, or $\mathrm{k}$ values (where $\mathrm{k}=\mathrm{X}_{\mathrm{S}}$ / $\mathrm{X}_{\mathrm{L}}$ ), for each element were then quantified using a modified Scheil-analysis $[10,11]$. 
Table 1 Alloy compositions under investigation (in wt.\%).

\begin{tabular}{||c|c|c|c|c|c|c|c|c|c|c|c|c||}
\hline Alloy & Ni & Al & Cr & Co & Mo & Ti & Nb & Ta & W & Re & Ru & Hf \\
\hline CMSX-4 & 61.7 & 5.6 & 6.5 & 9.0 & 0.6 & 1.0 & - & 6.5 & 6.0 & 3.0 & - & 0.1 \\
\hline RR3010 & 67.8 & 5.9 & 1.7 & 3.1 & 0.5 & 0.1 & 0.1 & 8.5 & 5.5 & 6.8 & - & 0.0 \\
\hline RR3010+1 Ru & 67.1 & 5.8 & 1.7 & 3.1 & 0.5 & 0.1 & 0.1 & 8.4 & 5.5 & 6.7 & 1.0 & 0.1 \\
\hline RR3010+3 Ru & 65.8 & 5.7 & 1.7 & 3.0 & 0.4 & 0.1 & 0.1 & 8.3 & 5.3 & 6.6 & 3.0 & 0.1 \\
\hline SRR300B & 62.5 & 5.8 & 4.0 & 8.0 & 2.2 & - & - & 7.5 & 4.6 & 5.3 & - & 0.1 \\
\hline SRR300B+1 Ru & 61.8 & 5.7 & 4.0 & 7.9 & 2.2 & - & - & 7.4 & 4.6 & 5.3 & 1.0 & 0.1 \\
\hline SRR300B+3 Ru & 60.5 & 5.6 & 3.9 & 7.8 & 2.1 & - & - & 7.3 & 4.5 & 5.2 & 3.0 & 0.1 \\
\hline SRR300C & 62.5 & 5.8 & 4.0 & 8.0 & 2.2 & - & - & 7.5 & 5.8 & 4.1 & - & 0.1 \\
\hline SRR300C+1 Ru & 61.9 & 5.7 & 4.0 & 7.9 & 2.2 & - & - & 7.4 & 5.7 & 4.1 & 1.0 & 0.1 \\
\hline SRR300C+3 Ru & 60.6 & 5.6 & 3.9 & 7.8 & 2.1 & - & - & 7.3 & 5.6 & 4.0 & 3.0 & 0.1 \\
\hline SRR300D & 62.5 & 5.8 & 4.0 & 8.0 & 2.2 & - & - & 7.5 & 5.2 & 4.7 & - & 0.1 \\
\hline SRR300D+1 Ru & 61.8 & 5.7 & 4.0 & 7.9 & 2.2 & - & - & 7.4 & 5.2 & 4.7 & 1.0 & 0.1 \\
\hline SRR300D+3 Ru & 60.5 & 5.6 & 3.9 & 7.8 & 2.1 & - & - & 7.3 & 5.1 & 4.6 & 3.0 & 0.1 \\
\hline SRR300E & 62.9 & 5.8 & 4.0 & 8.0 & 2.2 & - & 0.6 & 6.5 & 5.2 & 4.7 & - & 0.1 \\
\hline SRR300G & 63.5 & 5.8 & 4.0 & 8.0 & 3.5 & - & 0.6 & 6.5 & 4.0 & 4.0 & - & 0.1 \\
\hline SRR300H & 62.3 & 5.8 & 4.0 & 8.0 & - & - & - & 7.5 & 7.0 & 5.3 & - & 0.1 \\
\hline SRR300I & 61.8 & 5.8 & 5.5 & 8.0 & 2.0 & - & - & 7.5 & 4.0 & 5.3 & - & 0.1 \\
\hline SRR300L & 63.8 & 6.0 & 2.5 & 8.0 & 2.2 & - & - & 7.5 & 4.6 & 5.3 & - & 0.1 \\
\hline C17 & 60.7 & 6.0 & - & 12.0 & - & - & - & 6.0 & 9.3 & 6.0 & - & 0.1 \\
\hline C17+4.5 Cr & 58.1 & 5.7 & 4.5 & 11.5 & - & - & - & 5.7 & 8.9 & 5.7 & - & 0.1 \\
\hline C17+2.2 Mo & 59.4 & 5.9 & - & 11.7 & 2.2 & - & - & 5.9 & 9.1 & 5.9 & - & 0.1 \\
\hline C17+4.5 Cr+2.2 Mo & 56.9 & 5.6 & 4.5 & 11.2 & 2.2 & - & - & 5.6 & 8.7 & 5.6 & - & 0.1 \\
\hline \hline
\end{tabular}

The Scheil equation is:

$$
\mathrm{X}_{\mathrm{S}}=\mathrm{kX}_{\mathrm{O}}\left(1-\mathrm{f}_{\mathrm{S}}\right)^{(\mathrm{k}-1)}
$$

Where $X_{S}$ is the mole fraction of solute in the solid, $f_{S}$ is the volume fraction solid, $X_{O}$ is the nominal composition, or in this instance the average composition of each element as determined by the electron microprobe. The degree of segregation is related to the magnitude of the partition coefficient. No segregation occurs when $\mathrm{k}=1$, while coefficients greater and less than unity indicate that the corresponding element partitions preferentially to the solid and liquid, respectively, during solidification. The compositional data for the elements in each alloy measured at each point in the electron microprobe analysis was arranged into ascending or descending order depending on whether the element partitioned preferentially to the dendrite core or to the interdendritic regions. This was then plotted as a function of the volume fraction solid. The steeper the gradient of the curve, the more strongly the element segregates during solidification. To determine the solid-liquid partition coefficients, $\mathrm{k}$, for each of the constituent elements, the Scheil equation was fitted to the experimental data and then the value of $\mathrm{k}$ was adjusted until the best fit was achieved.

For many of the SRR300 alloys, levels of Co, Al and Hf were held constant while levels of $\mathrm{Cr}$, Mo, W, Re and $\mathrm{Ta}$ were systematically varied to investigate the effects of these additions on the resulting solidification characteristics. A simplified alloy, $\mathrm{C} 17$, with constant levels of $\mathrm{Co}, \mathrm{W}, \mathrm{Re}, \mathrm{Al}$, Ta and Hf was used to isolate the effects of $\mathrm{Cr}$ and Mo on the segregation behaviour of the constituent elements. Commercial single crystal superalloys CMSX-4 and RR3010 were also included in the analysis to serve as useful benchmarks against which the other experimental alloys could be compared. Four of the alloys, RR3010, SRR300B, SRR300C and SRR300D were doped with 1 and 3 wt.\% (0.6 and
1.9 at.\%) ruthenium. Ongoing investigations have demonstrated $\mathrm{Ru}$ to be a potentially beneficial alloying element that is capable of stabilising the microstructure against the formation of topologically close-packed phases at elevated temperatures [12, 13]. It was therefore considered important to observe whether such additions would be detrimental to the solidification characteristics of the alloy. It should be noted that the only difference between alloys SRR300B, SRR300C and SRR300D are the $\mathrm{W}$ and $\mathrm{Re}$ contents. Relative to this series of experimental alloys, SRR300B is high in Re, low in W, SRR300C is low in Re, high in W and SRR300D is intermediate between the two.

The solidus and liquidus temperatures of the $\mathrm{C} 17$ alloy series and the $\mathrm{Ru}$ bearing alloys were measured using Differential Scanning Calorimetry (DSC) to determine the change in freezing range with various elemental additions. Cylindrical samples $4 \mathrm{~mm}$ in diameter and $3 \mathrm{~mm}$ in height and weighing approximately $300 \mathrm{mg}$ were tested in a Netzsch DSC 404 at a heating rate of $10 \mathrm{~K} / \mathrm{min}$ from $1100^{\circ} \mathrm{C}$ up to $1500^{\circ} \mathrm{C}$ where the sample was held for 10 minutes and subsequently cooled at the same rate. The as-cast microstructures of these alloys were examined under the optical microscope following grinding, polishing and etching with Nimonic. The change in $\gamma / \gamma^{\prime}$ eutectic volume fraction with varying elemental additions was determined quantitatively using software based on an areal analysis. It has previously been shown [14] that the average areal fraction, $\mathrm{A}_{\mathrm{A}}$, obtained on twodimensional sections is an estimate of the volume fraction, $V_{V}$ :

$$
\mathrm{V}_{\mathrm{V}}=\sum \mathrm{A}_{\alpha} / \mathrm{A}_{\mathrm{T}}=\mathrm{A}_{\mathrm{A}}
$$

Where $\sum \mathrm{A}_{\alpha}$ is the sum of the areas of the phase of interest $\alpha$, in this case $\gamma / \gamma^{\prime}$ eutectic pools, and $A_{T}$ is the total measurement area. Five micrographs were taken of each sample using an optical microscope at 200x so as to gain a representative sample area and a statistically significant average volume fraction. 


\section{Results}

All of the samples were directionally solidified in a laboratoryscale Bridgman furnace as $\sim 12 \mathrm{~mm}$ diameter, $150 \mathrm{~mm}$ length bars under constant processing conditions and sectioned normal to the primary growth direction for microscopic analysis. Figures 1 and 2 reveal the dendritic as-cast structures for the RR3010 and C17 alloy series respectively. Pools of $\gamma / \gamma^{\prime}$ eutectic dispersed in the interdendritic regions are clearly distinguishable within the dendritic structure. Qualitative examination of the as-cast microstructures of each alloy set indicated that the $\gamma / \gamma^{\prime}$ eutectic content decreased with both increasing $\mathrm{Ru}$ content (Figures 1 (a)(c)) and $\mathrm{Cr}$ and Mo contents (Figures 2 (a)-(d)). In the base alloy a continuous distribution of eutectic around the dendrites is evident whereas the eutectic pools become more isolated and dispersed as the overall content of alloying additions increases.
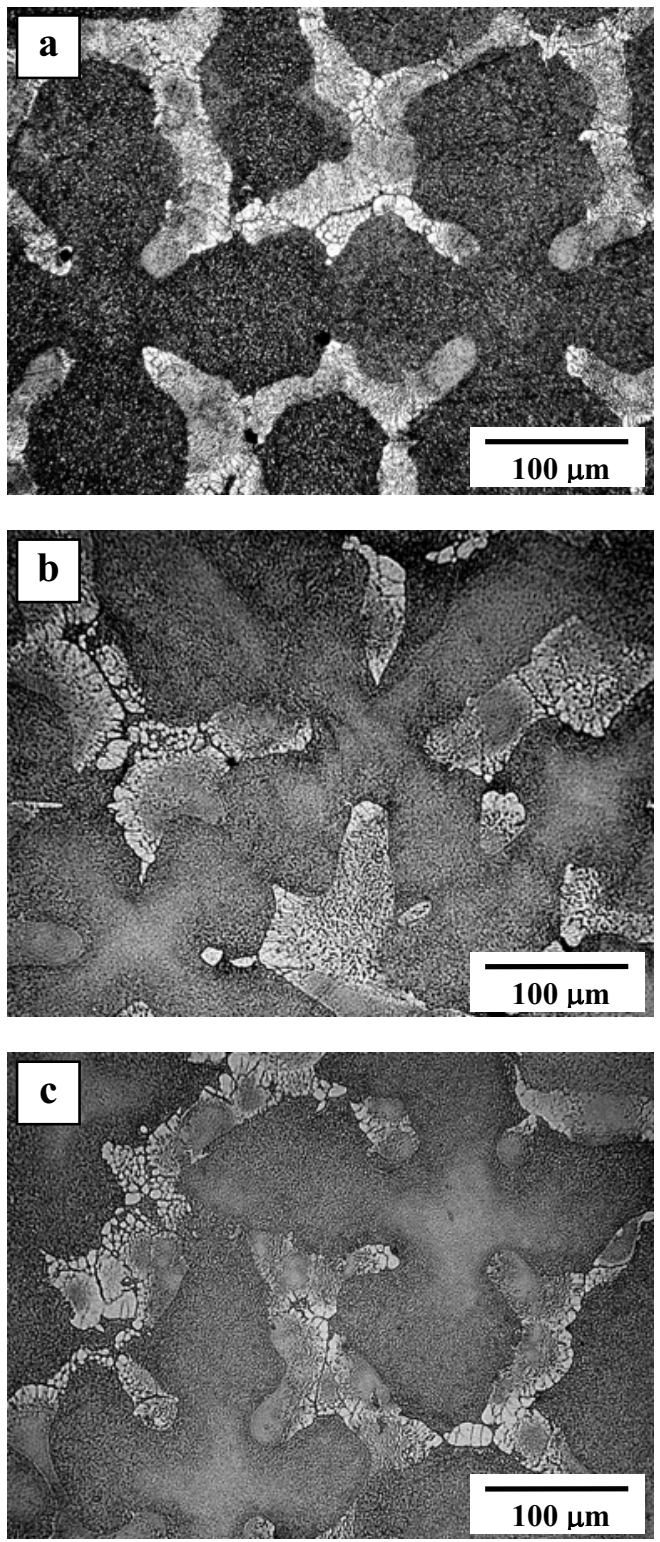

Figure 1 Optical micrographs of the as-cast microstructures of (a) RR3010 (b) RR3010 + $1 \mathrm{Ru}$ and (c) RR3010 + $3 \mathrm{Ru}$ showing decreasing levels of eutectic as ruthenium contents increase.
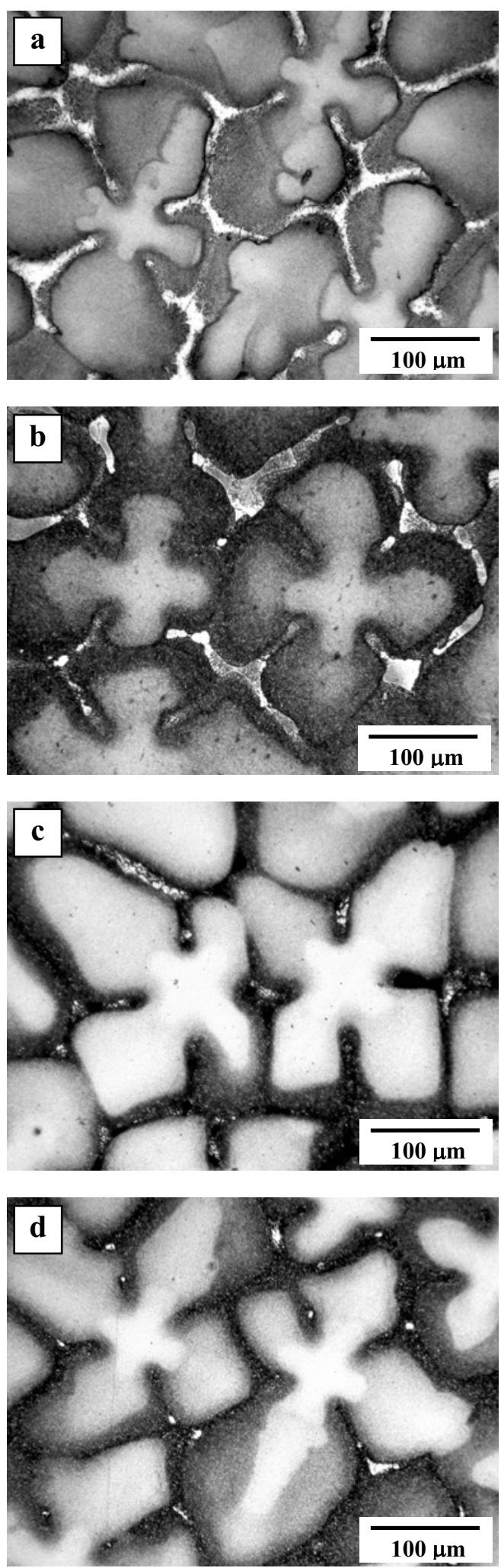

Figure 2 Optical micrographs of the as-cast microstructures of (a) $\mathrm{C} 17$ (b) $\mathrm{C} 17+2.2 \mathrm{Mo} \mathrm{(c)} \mathrm{C} 17+4.5 \mathrm{Cr}$ and (d) $\mathrm{C} 17+4.5 \mathrm{Cr}+$ 2.2 Mo showing decreasing levels of eutectic as $\mathrm{Mo}$ and $\mathrm{Cr}$ are added. 
This trend was confirmed quantitatively (Figures 3 and 4), where the volume fraction eutectic decreased at a rate comparable to the overall amount of alloying addition. For example, an addition of 4.5 wt.\% (5.2 at.\%) Cr decreased the eutectic content to a greater extent than an addition of $2.2 \mathrm{wt} . \%(1.4$ at.\%) Mo, while the least amount of eutectic was present in the alloy containing $6.7 \mathrm{wt} . \%$ (4.5 wt.\% $\mathrm{Cr}+2.2 \mathrm{wt} . \% \mathrm{Mo}$ ) of alloying additions. The volume fraction eutectic in alloys SRR300B and SRR300D followed a similar trend to SRR300C ranging from $\sim 10 \%$ and $\sim 11.5 \%$ in the base alloys to $\sim 7.5 \%$ and $\sim 7 \%$ in the 3 wt. $\% \mathrm{Ru}$ containing samples respectively.

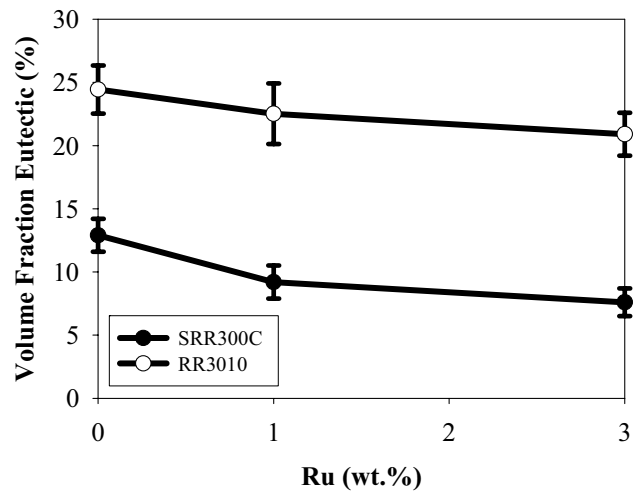

Figure 3 Quantitative analysis showing decreasing volume fraction eutectic with increasing $\mathrm{Ru}$ content.

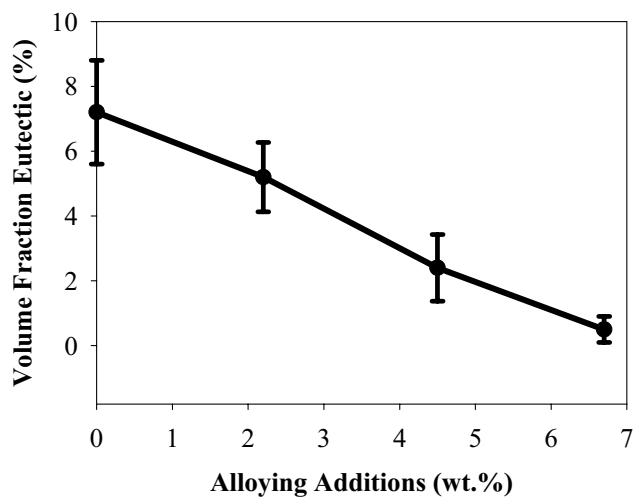

Figure 4 Quantitative analysis showing decreasing volume fraction eutectic with increasing Mo and Cr contents in C17.

The results from the segregation analysis are summarised in Table 2. Statistical fluctuations associated with the modified-Scheil analysis are all within an average deviation of 0.05 of the partitioning coefficients reported in Table 2. Generally, the more strongly segregating the element, the greater the average deviation. The high-density refractory elements, Ta, W and Re were found to segregate most severely during solidification i.e. their $\mathrm{k}$ values were furthest from unity. The degree to which each of these elements partitioned, however, varied significantly over the range of experimental alloys. Relative changes in both the Mo and $\mathrm{Cr}$ alloying levels were found to have the most significant effect. The presence of Mo and $\mathrm{Cr}$ in the SRR300 series of alloys was found to decrease the extent of segregation for the dense refractory elements known to promote freckle defects. For example, alloy SRR300I, which has the highest overall content of $\mathrm{Cr}+\mathrm{Mo}$, exhibits a substantially lower degree of segregation when compared to alloys SRR300L and SRR300H, which have similar levels of refractory alloying additions but lower $\mathrm{Cr}+\mathrm{Mo}$ levels. With an intermediate level of $\mathrm{Cr}+\mathrm{Mo}$, the measured segregation of Re, W and Ta in SRR300B is moderate when compared to SRR300I, SRR300L and SRR300H.

It is difficult to isolate the effects of $\mathrm{Cr}$ and Mo additions within the SRR300 series of alloys, since changes in their concentrations throughout the alloy compositions investigated are accompanied by significant changes in other important alloying elements. Hence in an attempt to isolate their effects, additions of $4.5 \mathrm{wt} . \%$ $\mathrm{Cr}$ and $2.2 \mathrm{wt} \%$ Mo were made systematically to the experimental Ni-based single crystal alloy containing no $\mathrm{Cr}$ and Mo additions, C17. The partition coefficients of the dense refractory elements in the base $\mathrm{C} 17$ alloy are far from unity and are comparable to RR3010 (Table 2), which is also a low Cr, low Mo content alloy. While the improvements in the solid-liquid partitioning coefficients of $\mathrm{W}$ and Re upon addition of $\mathrm{Cr}$ and $\mathrm{Mo}$ to $\mathrm{C} 17$ are not as dramatic as observed previously, the trends nonetheless are consistent with the prior findings, emphasising the decrease in segregation associated with the overall $\mathrm{Cr}$ and $\mathrm{Mo}$ content present within a given alloy. These effects are illustrated more clearly in Figure 5 where the segregation characteristics are clearly being influenced by the presence of $\mathrm{Cr}$ and Mo. In this particular set of alloys, Mo additions appear more potent than $\mathrm{Cr}$ in suppressing the segregation behaviour of the constituent elements. An addition of 2.2 wt.\% (1.4 at.\%) Mo decreases the microsegregation of $\mathrm{W}$ and $\mathrm{Re}$ to a greater extent than an addition of 4.5 wt.\% (5.2 at.\%) Cr. The largest decrease, however, was achieved when both $\mathrm{Cr}$ and Mo were added to $\mathrm{C} 17$. No significant improvements to the partitioning of Ta were noted upon addition of $\mathrm{Cr}$ and Mo.
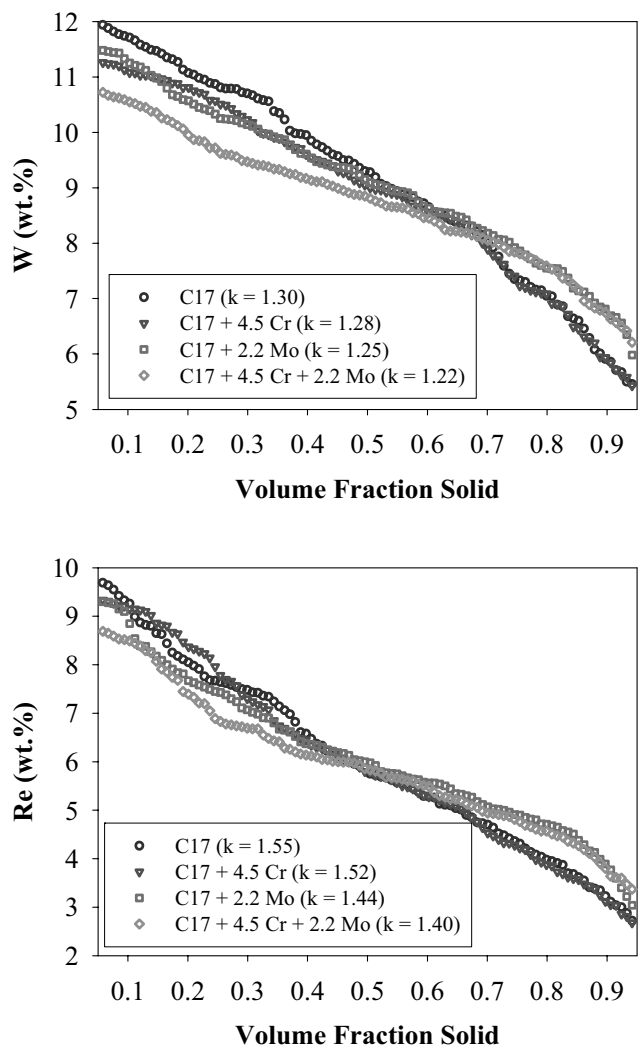

Figure 5 The effect of $\mathrm{Cr}$ and Mo additions on the solid-liquid partition coefficients of $\mathrm{W}$ and $\mathrm{Re}$ in $\mathrm{C} 17$. 
Table 2 Fitted solid-liquid partition coefficients for selected alloy compositions under investigation.

\begin{tabular}{||c|c|c|c|c|c|c|c|c|c||}
\hline Alloy & Ni & Al & Cr & Co & Mo & Ta & W & Re & Ru \\
\hline CMSX-4 & 0.97 & 0.91 & 1.05 & 1.06 & - & 0.76 & 1.29 & 1.47 & - \\
\hline RR3010 & 0.97 & 0.87 & 1.16 & 1.08 & - & 0.77 & 1.26 & 1.57 & - \\
\hline RR3010+1 Ru & 0.98 & 0.87 & 1.10 & 1.09 & - & 0.76 & 1.28 & 1.53 & 1.04 \\
\hline RR3010+3 Ru & 0.98 & 0.88 & 1.10 & 1.08 & - & 0.76 & 1.26 & 1.54 & 1.04 \\
\hline SRR300B & 0.97 & 0.92 & 1.11 & 1.06 & 1.10 & 0.79 & 1.21 & 1.38 & - \\
\hline SRR300B + 1 Ru & 0.98 & 0.90 & 1.04 & 1.05 & 1.07 & 0.75 & 1.24 & 1.33 & 1.04 \\
\hline SRR300B + 3 Ru & 0.98 & 0.90 & 1.04 & 1.05 & 1.06 & 0.74 & 1.24 & 1.34 & 1.04 \\
\hline SRR300C & 0.98 & 0.92 & 1.11 & 1.06 & 1.15 & 0.81 & 1.20 & 1.35 & - \\
\hline SRR300C+1 Ru & 0.98 & 0.90 & 1.05 & 1.06 & 1.08 & 0.73 & 1.21 & 1.32 & 1.03 \\
\hline SRR300C+3 Ru & 0.98 & 0.90 & 1.03 & 1.05 & 1.06 & 0.74 & 1.22 & 1.32 & 1.03 \\
\hline SRR300D & 0.97 & 0.91 & 1.11 & 1.07 & 1.09 & 0.77 & 1.23 & 1.48 & - \\
\hline SRR300D + 1 Ru & 0.98 & 0.93 & 1.06 & 1.05 & 1.07 & 0.80 & 1.18 & 1.33 & 1.04 \\
\hline SRR300D + 3 Ru & 0.98 & 0.91 & 1.03 & 1.05 & 1.06 & 0.77 & 1.22 & 1.39 & 1.04 \\
\hline SRR300E & 0.98 & 0.90 & 1.05 & 1.06 & 1.09 & 0.75 & 1.26 & 1.45 & - \\
\hline SRR300G & 0.98 & 0.95 & 1.06 & 1.04 & 1.08 & 0.83 & 1.19 & 1.28 & - \\
\hline SRR300H & 0.97 & 0.89 & 1.06 & 1.07 & - & 0.75 & 1.27 & 1.47 & - \\
\hline SRR300I & 0.98 & 0.95 & 1.08 & 1.04 & 1.09 & 0.87 & 1.12 & 1.23 & - \\
\hline SRR300L & 0.98 & 0.90 & 1.07 & 1.06 & 1.08 & 0.74 & 1.28 & 1.50 & - \\
\hline C17 & 0.95 & 0.85 & - & 1.05 & - & 0.67 & 1.30 & 1.55 & - \\
\hline C17+4.5 Cr & 0.96 & 0.85 & 1.03 & 1.05 & - & 0.63 & 1.28 & 1.52 & - \\
\hline C17+2.2 Mo & 0.96 & 0.87 & - & 1.05 & 1.10 & 0.68 & 1.25 & 1.44 & - \\
\hline C17+4.5 Cr+2.2 Mo & 0.97 & 0.88 & 1.03 & 1.05 & 1.10 & 0.68 & 1.22 & 1.40 & - \\
\hline \hline
\end{tabular}

To a lesser degree, Ru additions to RR3010, SRR300B, SRR300C and SRR300D were also observed to influence the solidification characteristics of the alloys, Table 2. Although slightly lower levels of $\mathrm{Cr}$, Mo and Re segregation were measured in alloys containing 1 and $3 \mathrm{wt} . \% \mathrm{Ru}$, these changes are negligible when compared to the effects of increasing the $\mathrm{Cr}$ and Mo content. $\mathrm{Ru}$ itself partitions only slightly to the dendrite core, having a $\mathrm{k}$ value close to unity.

Multiple linear regression analysis was performed on the experimental data to obtain formulae for the prediction of the solid-liquid partition coefficients of the major constituent elements. The formulae are:

$\mathrm{k}_{\mathrm{Cr}}=1.37-0.035$ wt. $\% \mathrm{Al}-0.01$ wt. $\% \mathrm{Cr}-0.00333$ wt. $\% \mathrm{Co}-$ 0.0068 wt. $\%$ Mo +0.0028 wt. $\%$ Ta -0.0094 wt. $\% \mathrm{~W}+0.0053$ wt. $\% \mathrm{Re}-0.0175$ wt. $\% \mathrm{Ru}$

$\mathrm{k}_{\mathrm{Mo}}=-0.02+0.154$ wt. $\% \mathrm{Al}+0.0147$ wt. $\% \mathrm{Cr}-0.00744$ wt. $\%$ Co +0.0151 wt. $\%$ Mo +0.00938 wt. $\%$ Ta +0.0216 wt. $\% \mathrm{~W}+$ 0.00208 wt.\% Re

$\mathrm{k}_{\mathrm{Ta}}=0.88+0.027$ wt. $\% \mathrm{Al}-0.00396$ wt. $\% \mathrm{Co}-0.0094$ wt. $\%$ Ta -0.0275 wt. $\% \mathrm{~W}-0.0049$ wt.\% Re -0.0095 wt.\% Ru

$\mathrm{k}_{\mathrm{W}}=1.97-0.091 \mathrm{wt} \% \mathrm{Al}-0.0177$ wt. $\% \mathrm{Cr}-0.0307$ wt. $\% \mathrm{Mo}-$ 0.015 wt. $\% \mathrm{Re}-0.0078$ wt.\% Ru

$\mathrm{k}_{\mathrm{Re}}=1.96-0.072$ wt. $\% \mathrm{Al}-0.0259$ wt. $\% \mathrm{Cr}-0.0035$ wt. $\% \mathrm{Co}-$ 0.0596 wt. $\%$ Mo +0.0138 wt. $\%$ Ta +0.0057 wt. $\%$ W -0.0066 wt. $\% \mathrm{Re}-0.0223$ wt. $\% \mathrm{Ru}$

The DSC results for the $\mathrm{Ru}$ containing alloys, their base counterparts and the $\mathrm{C} 17$ alloy series are listed in Table 3. In all cases the base alloy has the smallest freezing range. $\mathrm{Ru}$ for the most part decreases the solidus temperature and has a negligible effect on its liquidus, Figure 6. No notable change in the liquidus of $\mathrm{C} 17$ was observed upon alloying with Mo and $\mathrm{Cr}$ but both elements decreased the solidus, with the latter causing the largest reduction.

Table 3 DSC results for the Ru containing alloys and their base counterparts and the $\mathrm{C} 17$ alloy series.

\begin{tabular}{||c|c|c|c||}
\hline \hline Alloy & $\begin{array}{c}\text { Solidus } \\
\left({ }^{\circ} \mathbf{C}\right)\end{array}$ & $\begin{array}{c}\text { Liquidus } \\
\left({ }^{\circ} \mathbf{C}\right)\end{array}$ & $\begin{array}{c}\text { Freezing Range } \\
\left({ }^{\circ} \mathbf{C}\right)\end{array}$ \\
\hline RR3010 & 1373 & 1418 & 45 \\
\hline RR3010+1 Ru & 1366 & 1418 & 52 \\
\hline RR3010+3 Ru & 1365 & 1417 & 52 \\
\hline SRR300B & 1341 & 1401 & 60 \\
\hline SRR300B + 1 Ru & 1335 & 1398 & 63 \\
\hline SRR300B + 3 Ru & 1335 & 1401 & 66 \\
\hline SRR300C & 1338 & 1397 & 59 \\
\hline SRR300C + 1 Ru & 1340 & 1400 & 60 \\
\hline SRR300C + 3 Ru & 1340 & 1402 & 62 \\
\hline SRR300D & 1340 & 1398 & 58 \\
\hline SRR300D + 1 Ru & 1333 & 1397 & 64 \\
\hline SRR300D + 3 Ru & 1339 & 1403 & 64 \\
\hline $\mathrm{C} 17$ & 1399 & 1420 & 21 \\
\hline $\mathrm{C} 17+2.2 \mathrm{Mo}$ & 1392 & 1420 & 28 \\
\hline $\mathrm{C} 17+4.5 \mathrm{Cr}$ & 1381 & 1422 & 41 \\
\hline $\mathrm{C} 17+4.5 \mathrm{Cr}+2.2 \mathrm{Mo}$ & 1374 & 1420 & 46 \\
\hline
\end{tabular}




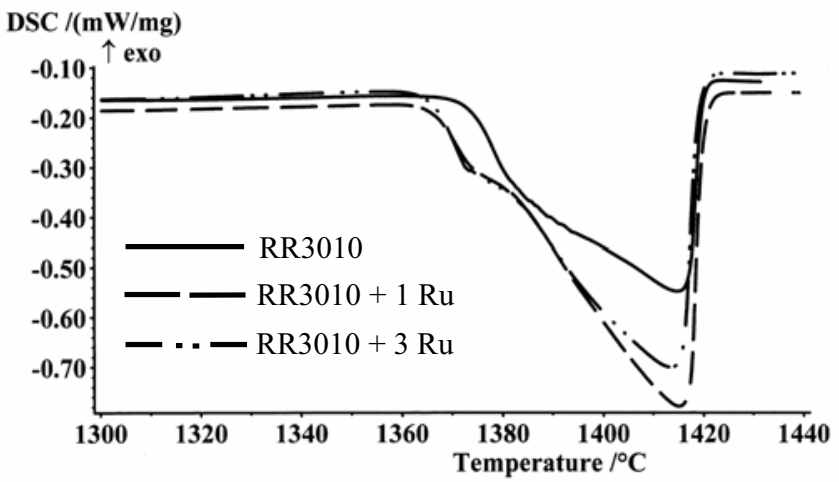

Figure 6 DSC curves illustrating the influence of Ru additions on the freezing range of RR3010.

\section{Discussion}

The magnitude of the coefficient associated with each of the elements in the linear regression analysis provides an indication of the relative influences of the other elements on the partitioning of the element in question. The equations for the elements known to be most important in the promotion of grain defects, namely $\mathrm{W}$ and $\mathrm{Re}$, show the potential benefits of $\mathrm{Cr}$, Mo and $\mathrm{Ru}$ additions in decreasing the susceptibility of an alloy to single crystal breakdown during solidification. Besides $\mathrm{Al}$, the coefficients for $\mathrm{Cr}$ and $\mathrm{Mo}$ in the determination of $\mathrm{k}_{\mathrm{W}}$ and $\mathrm{k}_{\mathrm{Re}}$ exert the largest influence. The coefficient for $\mathrm{Ru}$ is only significant in the formula for $\mathrm{k}_{\mathrm{Re}}$. With a smaller range of experimental data, larger statistical uncertainties are associated with the regression analysis of Ru.

The solidification characteristics of an alloy are controlled by the phases present in the as-cast microstructure, the freezing range and the overall thermodynamics of the system. To begin to explain the effect of $\mathrm{Cr}$ and Mo on the solid-liquid partitioning of $\mathrm{Re}$ and $\mathrm{W}$ and that of $\mathrm{Ru}$ on $\mathrm{Re}$, each of these factors were considered. During directional solidification under steady state conditions, the mushy zone is comprised of single phase $\gamma$ dendrites and liquid solute. Since the alloying additions in Ni-base superalloys tend to partition preferentially into either the $\gamma$ or $\gamma^{\prime}$ phases, limited solubility of $\gamma^{\prime}$ forming elements exists within the single phase dendrites during solidification. Hence, elements such as $\mathrm{Ta}, \mathrm{Al}$ and $\mathrm{Hf}$ become enriched into the liquid solute. The other alloying additions, $\mathrm{Re}, \mathrm{W}, \mathrm{Cr}, \mathrm{Co}, \mathrm{Mo}$ and $\mathrm{Ru}$, are soluble in the $\gamma$ phase and tend to partition preferentially to different degrees into the $\gamma$ dendrites during solidification. A reduction in the degree of microsegregation could occur if the respective alloying additions shifted the overall composition of the alloy closer to that of the $\gamma / \gamma^{\prime}$ eutectic. An initial composition further from the eutectic composition would enable segregation over a greater range prior to attainment of the eutectic composition, at which point the remaining liquid would solidify as eutectic and no further solid-liquid partitioning could take place. However, additions of $\mathrm{Cr}$, Mo and $\mathrm{Ru}$ were all shown to decrease both the degree of segregation and the volume fraction of eutectic in the as-cast condition, Figures 3 and 5 . The decrease in eutectic volume fraction was not unexpected since doping of the alloys with $\mathrm{Ru}, \mathrm{Cr}$ and Mo effectively diluted the system, thus drawing the composition of the alloy further from that of the eutectic. In addition, $\mathrm{Cr}$, Mo and $\mathrm{Ru}$ are primarily $\gamma$ rather than $\gamma^{\prime}$ formers so it would be unlikely that they would promote eutectic formation [15, $16]$.

The effect of $\mathrm{Cr}$, Mo and $\mathrm{Ru}$ on the temperature range over which segregation could occur was also investigated. Since the magnitude of the freezing range $\left(T_{S}-T_{L}\right)$ governs the extent of the mushy zone during directional solidification, minor changes could also influence the segregation characteristics of the alloy. Alloys that solidify over a relatively small freezing range are likely to exhibit minimal levels of $\mathrm{W}$ and Re segregation since the thermal fields are likely to have a larger influence than the solute fields during solidification. The results however, show for all the alloys investigated that the freezing range is narrowest for the undoped base alloys. Increases of $\sim 6^{\circ} \mathrm{C}$ were observed with 3 wt.\% $\mathrm{Ru}$ additions while $\mathrm{Cr}$ additions to $\mathrm{C} 17$ increased the freezing range by $\sim 20^{\circ} \mathrm{C}$. Coupled with the microstructural observations regarding the volume fraction of eutectic, results from this study indicate that the solidification characteristics are strongly dependent upon alloy composition. The combined level of $\gamma$ forming alloying additions (Re, W, Co, Cr, Mo and $\mathrm{Ru}$ ) present within the alloy appear to greatly influence the degree of segregation in the alloy.

As Ni-base superalloys become more heavily alloyed, supersaturation of the $\gamma$ phase with $\mathrm{Re}, \mathrm{W}, \mathrm{Co}, \mathrm{Cr}, \mathrm{Mo}$ and $\mathrm{Ru}$ during solidification could occur as the solubility limits are exceeded. Elements that tend to increase the liquidus temperature of $\mathrm{Ni}(\mathrm{Re}$ and $\mathrm{W}$ ), also tend to segregate most strongly to the single phase $\gamma$ dendrites during solidification. $\mathrm{Ru}$ is an unusual alloying addition as it slightly increases the liquidus temperature, but segregates only mildly to the $\gamma$ phase. Other $\gamma$ forming elements, $\mathrm{Co}, \mathrm{Cr}$ and $\mathrm{Mo}$, tend to slightly lower the liquidus temperature and segregate only moderately to the $\gamma$ phase during solidification. Based on the observed changes in microstructure and associated changes in freezing range, compositional changes associated with the $\mathrm{Cr}$, Mo and $\mathrm{Ru}$ additions appear to be altering the solid-solution solubility limits that govern segregation during solidification. In general, higher levels of refractory element segregation were measured in alloys containing low overall levels of the potent $\gamma$ forming elements. Based on atomic percentages, the lowest combined levels of $\mathrm{Re}, \mathrm{W}, \mathrm{Cr}$ and Mo are found in RR3010 and C17, 6.6 and 5.25 respectively. These alloys also exhibited the largest degree of segregation, with $\mathrm{k}_{\mathrm{Re}}$ of 1.57 and 1.55 and $\mathrm{k}_{\mathrm{W}}$ of 1.26 and 1.30 for RR3010 and $\mathrm{C} 17$ respectively. Alloys, such as SRR300G and SRR300I, which contain significantly higher levels (9.6 and 10.9 at.\%, respectively) of these potent $\gamma$ forming elements tend to result in less segregation during solidification $\left(\mathrm{k}_{\mathrm{Re}}\right.$ is 1.28 and 1.23 and $\mathrm{k}_{\mathrm{W}}$ is 1.19 and 1.12 for SRR300G and SRR300I respectively). These trends are also consistent with previous studies investigating the change in segregation associated with large changes in alloy composition [6]. Although the other $\gamma$ forming elements were also observed to influence segregation in these alloys, the degree of change was less significant. These findings suggest that strong interactions exist between $\mathrm{Cr}, \mathrm{Mo}, \mathrm{W}$ and Re; this may be due to the affinity that these elements have for one another as evidenced in the tendency for Cr-Re, Mo-Re and W-Re to combine to form stable intermetallic TCP phases.

Despite quantification of the mechanisms by which $\mathrm{Cr}$, Mo and $\mathrm{Ru}$ influence the solid-liquid partitioning of $\mathrm{W}$ and $\mathrm{Re}$, the observed effects of $\mathrm{Mo}$ and $\mathrm{Cr}$ are interesting especially considering the recent trends towards developing low chromium, 
low molybdenum content superalloys to minimise TCP formation at elevated temperatures. These changes may actually be detrimental to the manufacture and production of advanced single crystal components because of the increased tendency to form grain defects during solidification. The Mo and $\mathrm{Cr}$ contents in advanced alloys have been reduced, where for example in RR3010 they are now at 0.5 and $1.7 \mathrm{wt} . \%$ respectively. This trend is primarily associated with the destabilizing effect $\mathrm{Cr}$ and Mo have on the $\gamma-\gamma^{\prime}$ microstructure after prolonged exposures at elevated temperatures. Minimization of these elements have enabled advanced Ni-based single crystals to be alloyed with increasing levels of potent solid solution strengtheners, such as W and $\mathrm{Re}$, to enhance the high temperature creep properties [13]. $\mathrm{Cr}$ is typically maintained at sufficient concentrations to provide a certain level of hot corrosion and oxidation resistance. As the overall content of Re has increased however, the price of bar stock has increased so improvements in yield are of greater importance. The results from this investigation suggest that the intrinsic tendency of high refractory $\mathrm{Ni}$-based single crystal alloys to form grain defects during solidification can potentially be decreased by increasing the overall level of $\mathrm{Cr}$ and $\mathrm{Mo}$ in the alloy. Both of these elements appear to reduce the extent of microsegregation of the dense refractory elements $\mathrm{W}$ and Re during solidification known to cause single crystal breakdown. While increased levels of both $\mathrm{Cr}$ and Mo promote TCP formation, this could potentially be controlled through the addition of ruthenium [12]. Preliminary studies suggest that $\mathrm{Ru}$ can be added in the concentration necessary to improve microstructural stability without significant detriment to the solidification characteristics of the alloy. In fact, it may prove beneficial by further reducing the extent of $\mathrm{Re}$ microsegregation. Moreover, the decreased level of microsegregation accompanying increases in $\mathrm{Mo}$ and $\mathrm{Cr}$ contents would reduce the extent of local Re supersaturation in the as-cast crystals and enable homogenisation to occur more rapidly during solution-heat treatment.

\section{Conclusions}

- $\mathrm{Cr}$ and Mo additions reduce the degree to which Re and W partition to the dendrite core during solidification.

- $\mathrm{Ru}$ partitions only slightly to the dendrite core during solidification and marginally reduces the solid-liquid partition coefficients of Re.

- Additions of 4.5 wt.\% (5.2 at.\%) $\mathrm{Cr}$ and 2.2 wt.\% (1.4 at.\%) Mo to the experimental alloy $\mathrm{C} 17$ and 1 and 3 wt.\% (0.6 and 1.9 at.\%) Ru to alloys SRR300B, SRR300C and SRR300D all decreased the volume fraction eutectic in the as-cast microstructure.

- The same additions of $\mathrm{Cr}$ and Mo to $\mathrm{C} 17$ increased the freezing range of the alloy by $\sim 20^{\circ} \mathrm{C}$ and $\sim 7^{\circ} \mathrm{C}$ respectively, while $3 \mathrm{wt} . \% \mathrm{Ru}$ increased the freezing range of the SRR300 range of experimental alloys to which it was added by $\sim 6^{\circ} \mathrm{C}$.

- Compositional changes associated with $\mathrm{Cr}$, Mo and $\mathrm{Ru}$ additions appear to reduce the extent of $\mathrm{Re}$ and $\mathrm{W}$ microsegregation by altering the solid-solution solubility limits that govern segregation during solidification.

\section{References}

[1] S. Kalpakjian. Manufacturing Engineering and Technology. Addison-Wesley, New York, $2^{\text {nd }}$ edition, 1992.
[2] M. Levy, R. Hule, and F. Petit. Oxidation and Hot Corrosion of some Advanced Superalloys at $1300-2000^{\circ} \mathrm{F}\left(704-1093^{\circ} \mathrm{C}\right)$. Corrosion, volume 45, page 661, 1974.

[3] R. F. Singer. New Materials for Industrial Gas Turbines. Mater. Sci. and Tech., volume 3, page 726, 1987.

[4] M.S.A. Karunaratne, D.C. Cox, and R.C. Reed. Modelling of Microsegregation in CMSX-4 Superalloy and its Homogenisation During Heat Treatment. In Superalloys 2000, pages 263-272. TMS AIME, Warrendale PA, USA, 2000.

[5] T.M. Pollock, W.H. Murphy, E.H. Goldman, D.L. Uram, and J.S. Tu. Grain Defect Formation During Directional Solidification of Nickel Base Single Crystals. In Superalloys 1992, pages 125134. TMS AIME, Warrendale PA, USA, 1992.

[6] S. Tin, T.M. Pollock, and W.T. King. Carbon Additions and Grain Defect Formation in High Refractory Nickel-Base Single Crystal Superalloys. In Superalloys 2000, pages 201-210. TMS AIME, Warrendale PA, USA, 2000.

[7] V.A. Wills and D.G. McCartney. A Comparative Study of Solidification Features in Nickel-Base Superalloys: Microstructural Evolution and Microsegregation. Mater. Sci. Eng., volume 145(2), pages 223-232, 1991.

[8] J. Zou, H.P. Wang, R. Doherty and E.M. Perry. Solidification Behaviour and Microstructure Formation in a Cast Nickel Based Superalloy: Experiment and Modeling. In Superalloys 1992, pages 165-174. TMS AIME, Warrendale PA, USA, 1992.

[9] K.L. Zeisler-Mashl and B.J. Pletka. Segregation During Solidification in the MAR-M247. In Superalloys 1992, pages 175184. TMS AIME, Warrendale PA, USA, 1992.

[10] M.N. Gungor. A Statistically Significant Experimental Technique for Investigating Microsegregation in Cast Alloys. Met. Trans. A., volume 20(A), pages 2529-2533, 1989.

[11] S. Tin and T.M. Pollock. Predicting Freckle Formation in Experimental Single Crystal Ni-Base Superalloys. Met Trans A, volume 34(A), pages 1953-1967, 2003.

[12] P. Caron. High $\gamma^{\prime}$ Solvus New Generation Nickel-Based Superalloys for Single Crystal Turbine Blade Applications. In Superalloys 2000, pages 747-756. TMS AIME, Warrendale PA, USA, 2000.

[13] K.S. O'Hara, W.S. Walston, E.W. Ross, and R. Darolia. General Electric Company, US Patent \# 5,482,789, 1996.

[14] G. F. Vander Voort. Metallography: Principles and Practice page 426. McGraw-Hill Inc., New York, 1984.

[15] E. W. Ross and C. T. Sims. Superalloys II, chapter 4 Nickel-Base Alloys, pages 97-134. eds. C. T. Sims et. Al., Wiley, New York, 1987.

[16] Y. Zheng, X. Wang, J. Dong, Y. Han, H. Murakami and H. Harada. Effect of Ru Addition on Cast Nickel Base Superalloy with Low Content of $\mathrm{Cr}$ and High Content of W. In Superalloys 2000, pages 305-311. TMS AIME, Warrendale PA, USA, 2000. 
